\title{
fMRI Response During Visual Motion Stimulation in Patients with Late Whiplash Syndrome
}

\author{
1P. Freitag, ${ }^{2}$ M.W. Greenlee, ${ }^{3}$ K. Wachter, ${ }^{3}$ Th.M. Ettlin, and ${ }^{1}$ E.W. Radue
}

Whiplash injuries are caused by a sudden acceleration of the trunk with hyperextension, hyperflexion, or hyperlateroversion of the neck. The symptoms experienced by these patients vary from neck pain, headache, vertigo, nausea, to emotional and cognitive disturbances, especially in concentration and attentional processing (1). In 1-year

From the 'Department of Neuroradiology, University Hospital Basel, Basel, Switzerland; 'Department of Neurology, University of Freiburg, and Institute for Cognitive Science, University of Oldenburg, Germany; and ${ }^{3}$ Rehabilitation Clinic Rheinfelden, Rheinfelden, Switzerland.

Address correspondence and reprint tequests to Peter Freitag, M.D., Department of Neuroradiology, University Hospital Basel, Petersgraben 4, CH-4031 Basel, Switzerland. E-mail: pfreitag@uhbs.cli follow-up studies, some authors $(2,3)$ have reported that up to $24 \%$ of these patients develop chronic symptoms. Patients with whiplash injuries also exhibit reduced reading capabilities due to disturbed oculomotor control (4).

Resting perfusion single-photon-emission computed tomography (SPECT) and positron emission tomography (PET) found decreased temporoparietooccipital (TPO) tracer uptake among long-term symptomatic patients with late whiplash syndrome (5-8). Interestingly, this decreased resting perfusion in SPECT imaging was found both in chronic symptomatic and asymptomatic persons with a history of whiplash trauma. The underlying pathophysiologic process remains largely unknown (9).

The TPO region has been shown to be one of the important cortical sites of visual motion processing. The 
results of PET and functional magnetic resonance imaging (fMRI) studies in healthy subjects who viewed motion displays indicate that the human homolog of the motion-selective areas MT (middle temporal) and MST (middle superior temporal), which are also teferred to as the fifth visual area and its adjacent area (V5/V5a) in monkeys, are located in that region (10-15). To explore whether dysfunction of this cortical region might correlate with some of the symptoms of late whiplash syndrome, we addressed following issues:

1. Is motion perception impaired in patients with late whiplash syndrome?

2. Is the AMRI response to visual motion stimulation altered in the TPO region?

3. Are there differences between symptomatic patients with late whiplash syndrome and asymptomatic patients after whiplash trauma?

4. Is there a correlation between motion perception and fMRI results?

We measured visual motion perception with a wellestablished psychophysical test and PMRI in symptomatic patients with late whiplash syndrome, in asymptomatic patients after whiplash trauma and in a control group without history of trauma. To exclude macroscopic brain damage a $T_{2}$-weighted MRI of the brain was also performed.

\section{Methods}

Clinical testing of visual motion perception was performed in patients and volunteers on a Mac $7600 \mathrm{com}$ puter. The display program produced animated sequences of 60 sparsely spaced black dots on a medium grey background (mean luminance, $30 \mathrm{~cd} / \mathrm{m}^{2}$ ). The motion sequences were designed to simulate frontoparallel motion within two fields ( $5 \times 5$ degrees). The dot motion had a constant speed of 6 degrees/s. One field of dots was positioned in the left visual field, and the other was presented in the right visual field (see inset in Fig. 1). One field contained dots with random directions, whereas the other field contained dots with a mixture of random and coherent directions (left or right). Eight levels of motion coherence were presented in a random order. The coherent motion was randomly added to the left or right motion field. The subjects were asked to fixate on a central fixation spot and to report which of the two fields contained coherent motion (i.e., detection). Viewing distance was fixed at $0.57 \mathrm{~m}$ with the help of a chin-rest. Each trial consisted of a 0.5 -s period in which both fields were simul taneously presented. The subject responded in a two-alternative forced-choice paradigm: which field contained the coherently moving dots. The investigator was blind with respect to the patients' and volunteers' history. All subjects were given a few trials to become acquainted with the task and the stimulus displays. They were instructed to maintain fixation throughout each trial and to respond quickly.

fMRI was performed in a separate session on another day with a 1.5-T Siemens Magnetom Vision using $T_{2^{*-}}$ weighted echo planar imaging (TE, $70 \mathrm{~ms}$; flip angle, 90 degrees; FOV, $250 \mathrm{~mm}$; matrix, $128 \times 128 ; 12$ contiguous 5 -rimm slices, resulting in a voxel size of $1.95 \times 1.95$ $\times 5 \mathrm{~mm}$. Slice orientation was positioned oblique to the axial plane through the striate and extrastriate visual cortices). A 3-D high-resolution data set was performed using a $T_{1}$-weighted MP-Rage (magnetization-prepared, rapid acquisition gradient echo) sequence with a $1 \times 1$ $\times 1$-min voxel size. This anatomic data set was used to normalize and transform the functional data of each individual subject into the Talairach space (16). We used the software package BrainTools by Krish Singh (17) to analyze the functional data. This included 2-D motion correction, coregistration, normalization, and smoothing with a gaussian filter (SD, 2 voxels).

To minimize head motion, the subject's head was fixed using a vacuum cap. Residual in-plane motion was corrected by applying an image-correction algorithm (18). In two cases, excessive out-of-plane motion was detected, and the entire examinations of these two patients were excluded from further analysis. During the MRI sessions, subjects viewed the stimuli through a plexiglass prism that was positioned directly above the window of the Siemens headcoil. The stimuli were created on a Macintosh computer and back-projected onto a translucent screen within the gantry using a LCD Projector (Sony). The image subtended 60 degrees in width and 30 degrees in height (corresponding to $180 \times 90$ pixels on the display). The stimulation protocol consisted of twelve 50-s intervals. Within each interval, ten volumes were acquired. A baseline resting period (fixation point and static dots) alternated with either a period of randomly moving dots (stimulation 1) or a period of coherently moving dots (stimulation 2). Dot motion was constant at 6 degrees/5. During the coherent motion condition, the coherence level was constant at $90 \%$. Both fMRI experiments in each patient were performed during the same session. In the first experiment, the subjects were instructed to maintain fixation throughout the run. In the second experiment, subjects were asked to pursue with their eyes the coherently moving dots. The order of the experiments was kept constant, to exclude additional variation within the groups due to habituation effects. 


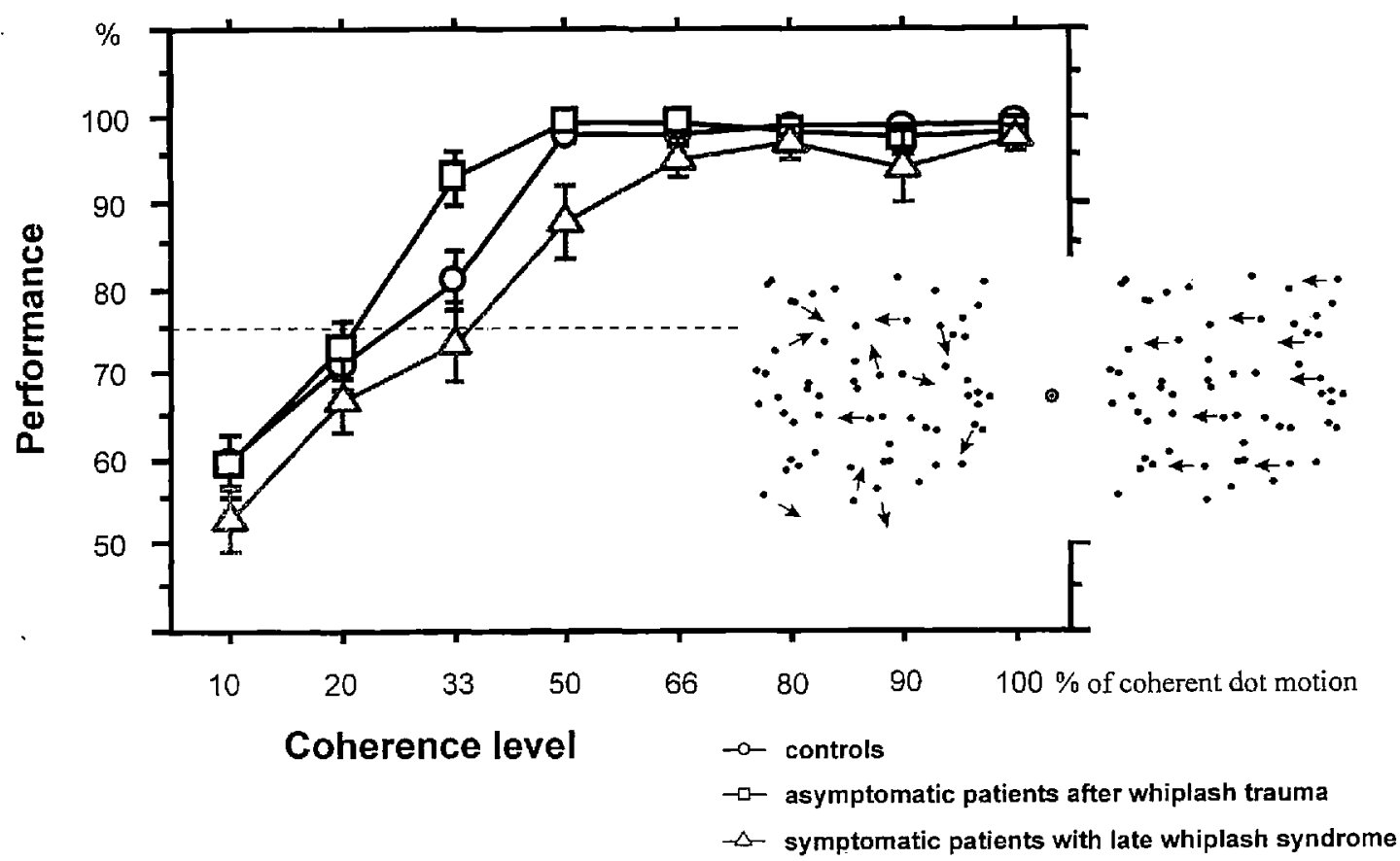

Figure 1. Results of psychophysical estimate of coherent motion thresholds. The inset demonstrates an example of the display for the psychophysical testing of visual motion perception. The error bars show the $95 \%$ confidence incerval; the dashed line represents $75 \%$ correct performance.

Eye movements were monitored with MR-compatible electrooculogram (EOG) (19). Patients and volunteers who did not follow the instructions could thus be excluded. Two patients were excluded from the study, either owing to excessive head motion, to compliance problems, or to both.

The study was approved by the local ethics committee, and all subjects gave written informed consent.

\section{Subjects}

The studies of five patients (age, 31-58 years; mean, 43.2 years) with late whiplash syndrome grade II Quebec Classification (20) could be evaluated. The illness duration was 14-34 months (mean, 26.2 months). All patients were unable to work (inclusion criteria), and all were investigated with a neuropsychological test battery. The symptoms of the patients included cervicalgia, headache, cognitive disturbances, and lumbovertebral symptoms. All patients were highly motivated in further investigation of their complaints and thus interested in the performed experiments.

Five asymptomatic patients after whiplash trauma (age, 31-45 years; mean, 33.2 years) but without any per- sisting symptoms or testrictions in daily life were also studied.

- Seven healthy volunteers without history of trauma (age, 27-53 years; mean, 35.0 years) formed the control group. These subjects were recruited from the hospital staff.

Patients and volunteers were naive with regards to the experimental aims and AMRI methods. The experimenter (M.W.G.) was blind with respect to the group classification of the subjects during psychophysical testing.

Exclusion criteria were as follows: Any medication interfering with central nervous system (CNS) function $24 \mathrm{~h}$ before each examination; any other medical or neurologic disease interfering with CNS function; or any psychiatric, otologic, or ophthalmologic disorders (as determined by standard screening procedures).

\section{Data Analysis}

Psychometric functions, relating performance to coherence level, and coherent motion thresholds ( $75 \%$ performance level) were calculated. An analysis of variance (ANOVA) was conducted on the performance data to determine the effects of experimental group, coherence 
level, hemisphere, and task. In the fMRI experiments, the time course of significantly activated clusters was inspected and compared with the stimulus time course. $\mathrm{BOLD}$ response levels in regions-of-interest ( $\mathrm{ROI}$ ) in V5 on each hemisphere were determined across the different stimulus conditions, tasks, and groups respectively. The ROI was determined based on anatomic and functional landmarks in the T1 and activation images. Once the ROI was positioned in each hemisphere, its location was constant over all measurements. The values entered into the ANOVA are based on the average BOLD signal (SD of voxel time course $X$ normal correlation coefficient) without a threshold.

\section{Results}

Diagnostic whole brain $T_{2}$-weighted MRI of all patients and volunteers showed no evidence of structural damage.

\section{Coherent Motion Thresholds}

The results of the psychophysical measurements of coherent motion perception are shown in Fig. 1. Ccmpared with the controls, symptomatic patients required a significantly larger portion of coherently moving dots to detect the coherent motion. There were no significant differences between the volunteers and asymptomatic patients after whiplash trauma (Fig. 1). If anything, the asymptomatic patients tended to perform slightly better than the control subjects. The mean threshold levels corresponded to $33 \%, 20 \%$, and $25 \%$ coherence level for $75 \%$ correct performance in the symptomatic and asymptomatic patients and the control subjects, respectively. We found no effects of hemifield (left or tight visual field) or stimulus direction (leftward or rightward).

\section{$f M R I$ Findings}

With EOG we typically observed some eye blinks occurring with a similar frequency for baseline and stimulation periods during the MRI experiments for patients and volunteers. The EOG traces indicated that all subjects followed the instructions (fixation and pursuit). During fixation, we did not find significant optokinetic nystagmus during the motion stimulation, suggesting that the patients and controls could suppress reflexive eye movements. Compared with the other two groups, the symptomatic patients, however, showed a tendency to exhibit saccadic pursuit during the smooth pursuit task.

The AMRI activicy in the region of interest of the MT/MST area during visual motion perception random dot motion versus stationary dots showed no significant difference between all three groups $\left(F_{2,16}=0.51 ; \mathrm{NS}\right)$. All subjects in each of the three groups showed significant activation levels in the MT/MST region during random dot motion, but this activation level does not significantly differ across groups.

The results of the ROI analysis of the coherent motion comparisons are shown in Fig. 2 separately for the condition requiring fixation (left half) and the condition requiring pursuit (right half). The mean BOLD responses in the MT/MST region during coherent motion perception with fixation revealed a significant increase in each group compared with the condition with random dot motion, but the level of increase varied between symptomatic patients and controls but not between asymptomatic patients and controls (Fig. 2). This trend resulted in a significant difference $(p=0.037)$ in the AMRI response during coherent motion perception between symptomatic patients and the other two groups. Using the Scheffé test for post hoc pairwise comparisons, we could confirm that the difference arose between the symptomatic patients and the other two groups (for each comparison, $\mathrm{p}<0.05$ ). There was also an increase of the fMRI activity in the ROI of the MT/MST area between fixation and pursuit of the coherent dot motion in each group. This replicates an earlier fMRI study of our group in healthy volunteers regarding the $\mathrm{AMRI}$ activity changes and the location of the V5/V5a complex (19). The BOLD response was significantly lower in the symptomatic patients with late whiplash syndrome compared with the asymptomatic patients or with the control group.

The ANOVA revealed significant main effects for the following factors. The main effect of group (symptomatic, asymptomatic, and controls) was significant for the ROI over MT/MST (V5/V5a) during coherent motion perception $\left(F_{2,16}=4.6 ; \mathrm{p}<0.05\right)$. The difference was mainly related to the difference between symptomatic patients and the control group (Scheffé pairwise post hoc comparisons). The main effect of task (fixation or pursuit $)$ was also significant $\left(F_{1,33}=7.9 ; \mathrm{p}<0.01\right)$. The main effect of stimulus condition (random noise vs. coherent motion during fixation) was not significant.

On an individual basis (across groups), the comparison between age and AMRI response in MT/MST (V5/V5a) during random dot motion and coherent motion showed no significant correlation. Also the age differences between groups were not significant. There were no significant gender differences in the fMRI results. 


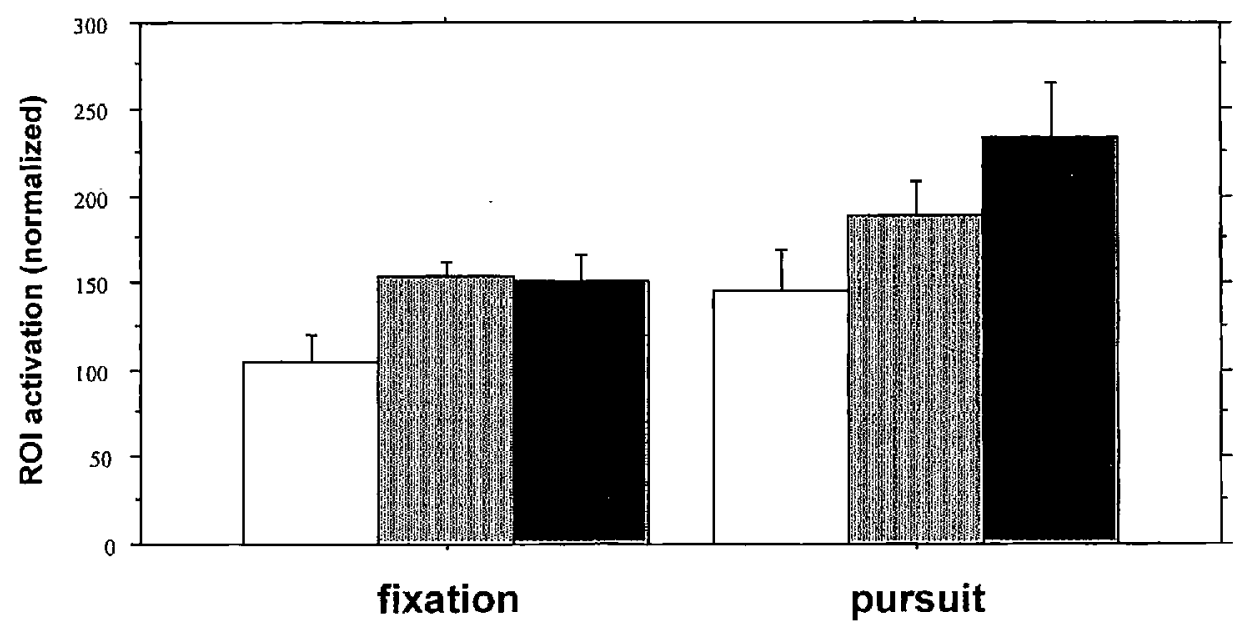

symptomatic patients with late whiplash syndrome
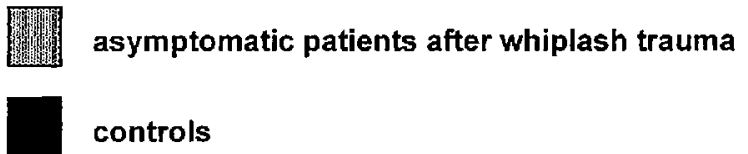

Figure 2. Functional magnetic resonance imaging (fMRI) results of the region of interest (ROI) analysis in V5 for the condition coherent dot motion with fixation or pursuit (averaged over both hemispheres). The error bars show the $95 \%$ confidence interval.

\section{Discussion}

There is an ongoing debate whether whiplash is a valid injury or a cultural phenomenon (2I-24). Objective findings are needed and could help the patients to understand their symptoms better.

In this study, symptomatic patients with late whiplash syndrome showed a significantly decreased performance in psychophysical tasks of coherent motion detection and corresponding AMRI activation in MT/MST compared with asymptomatic patients after a whiplash trauma and with healthy volunteers. These findings are in contrast to the nuclear imaging studies of Otte (5-8), who found decreased resting perfusion HMPAO-SPECT in the TPO region in symptomatic and asymptomatic patients after whiplash trauma. The results of these SPECT findings in the TPO region in whiplash parients have also recently been placed in question by Bicik et al. (25). In their resting perfusion ['sF]glucose PET and HMPAOSPECT study, they found no parietotemporal perfusion deficit in patients with late whiplash syndrome compared with controls. In a study with patients after traumatic brain injuries, Ichise et al. (26) found with HMPAOSPECT temporal perfusion abnormalities in $40 \%$, but only in $5 \%$ parietal and in $2 \%$ occipital perfusion deficits.
It should be noted that all SPECT data were acquired during rest, whereas the fMRI result is based on the difference between the resting and activated state, and as such, they are not directly comparable.

Although we did not find differences berween asympromatic patients and controls, we found signifjcantly less $\mathrm{AMRI}$ activation in the MT/MST complex in patients with late whiplash syndrome. The decreased performance in visual motion perception and fMRI response during coherent visual motion perception in symptomatic patients with late whiplash syndrome reported here suggests that a functional impairment in this extrastriate visual area is evident.

The ability to focus attention on objects in the peripheral visual field might also be impaired in late whiplash syndrome. Impaired visual attention could, in part, underlie the increased thresholds for coherent motion shown by the symptomatic patients. During the fMRI experiment, the coherent morion paradigm was interleaved with stationary dots and random dot motion during the fixation and pursuit task. There was no significant difference of the PMRI activity between patients and volunteers in the random dot motion perception condition. This serves as a control condition that speaks against substantial attentional effects across groups. 
In a previous study (19), we reported an increase in fMRI response duting pursuit compared with a fixation task. Other studies without eye movements showed the attentional influence on the AMRI activation during visual perception (27-29), so that the increase in our study is at least partly due to an attentional effect. Our patients with late whiplash syndrome reported difficulties following the coherent moving dots during the pursuit task. Their difficulty in pursuit was also evidenc in the EOO recordings. This reduced capability to perform smooth pursuit eye movements might influence the fMRI results in the pursuit condition. However, differences in the AMRI response were also evident during the fixation task, which could be done properly by all subjects. The significantly reduced AMRI response of the symptomatic patients in the fixation and pursuit task points to a perception deficit. Disturbed eye-movement control could thus be a consequence of this perceptual impairment. Impaired control of saccadic eye movements during reading and pursuit eye movements (4) have also been reported in patients with late whiplash syndrome.

Lesions of the TPO region have been shown to impair visual motion processing $(30-33)$ and reduce the gain of pursuit $(34,35)$. In our study, macroscopic brain damage was ruled out with diagnostic brain MRI. Thus, the disturbed motion processing revealed in symptomatic whiplash patients might be a consequence of microscopic damage within the cortical region or to the disconnection of projections from and into these motion-sensitive areas. Otherwise, although highly motivated, these patients experienced ongoing pain, and some of them, anxiety or depression. These symptoms might also lead to sleep disturbances. The possible influence of this on specific task-related activities is unknown.

For technical reasons, we were unable to perform whole-brain AMRI. However, within the scanned volume, we could not detect significant BOLD responses in other brain areas. Functional impaiment of other brain areas, connected to MT/MST, but outside of the acquired volume, might bc the origin of the observed differences between our patient groups.

In conclusion, using fMRI and psychophysical tests of motion perception, it was possible to observe differences between chronic symptomatic and asymptomatic patients after whiplash trauma. These results suggest an impairment in the MT/MST (V5/V5a) region with respect to motion processing. Microscopic structural and primary or secondary functional impairment cannot be differentiated in this study. Further studies with wholebrain fMRI should investigate larger groups of patients after whiplash trauma as well as other chronic diseases to evaluate the diagnostic relevance of $\mathrm{AMRI}$ or clinical psychophysical testing of visual motion perception to find a valid tool in diagnostic process in patients with late whiplash syndrome.

\section{References}

1. Kischka U, Ettlin TM, Heim S, et al. Cerebral sypmtons following whiplash injury. Eur Netrol 1991;31:136-40.

2. Jacobs A., Put E, lngels $M$, et al. One year follow-up of technetium-99m-HMPAO SPECT in mild head injury. J Nucl Med $1996 ; 37: 1605-9$.

3. Radanov BP, Sturzenegger $M$, Schnidrig A. Relationship between early' somatic, radiological, cognitive and psychological findings and outcome during a one-year follow-up in 117 patients suffering from common whiplash. BrJ Rheum 1994;33:442-8.

4. Gimse R, TjelI C, Bjorgen IA, et al. Disturbed eye movements after whiplash due to injury to the posture control system. J Clin Exp Neuropsychol 1996; I 8:178-86.

5. Otte A, Etelin TM, Fierz L, et al. Brain perfusion patterns in 136 patients with chronic symptoms after torsion of the cervical spine using single phoron emission compured tomography, technerium$99 \mathrm{~m}-\mathrm{HMPAO}$ and technetium-99m-ECD: a controlled study. J Vase Invest 1997;3:1-5.

6. Otte A, Etelin TM, Mueller-Brand J. Comparison of $99 \mathrm{~m}-\mathrm{Tc}-\mathrm{ECD}$ with $99 \mathrm{~m}$-Tc-HMPAO-brain-SPECT in late whiplash syndrome. J Vasc Invest 1995;1:157-63.

7. Otre A, Ettlin TM, Nitzsche EU, et al. PET and SPECT in whiplash syndrome: a new approach to a forgotten brain? JNNP $1997 ; 63: 368-72$.

8. Otte A, Mueller-Brandt J, Fierz L. Brain SPECT findings in late whiplash syndrome. Lancet 1995;345:1513-4

9. Alexander MP. In the pursuit of proof of brain damage after whiplash injury. Neurology 1998;51:336-40.

10. Corbetta $M$, Miezin FM, Dobmeyer $S$, et al. Selective and divided attention during visual discriminations of shape, color and speed: functional anatomy by positron emisssion tomography. I Neurosci $1991 ; 1: 2383-402$.

11. Zuki S, Watson JDG, Lueck CJ, et al. A direct demonstration of functional specialization in human visual cortex. I Neurosci 1991;11:641-9.

12. Watson JD, Myers R, Frackowiak RS, et al. Area V5 of the human brain: evidence from a combined study using positron emission tomography and magnetic-resonance inaging. Cereb Cortex 1993;3:79-94.

13. Cheng K, Fujita H, Kanno l, ec al. Human cortical regions activated by wide field visual motion: An H215O PET sudy. I Neurophysiol 1995; 74:413-27.

14. Tootell RHB, Mendola JD, Hadjikhani NK, et al. Functional analysis of V3A in related areas in human visual contex. I Neurosci 1995;17:7060-78.

15. Dupont P, De Bruyn B, Vandenberghe R. The kinetic occipital region in human visual cortex. Cereb Cortex 1997;7:283-92.

16. Talairach J, Tournoux P. Co-planar stereotaxic aths of the human brain. Stuttgart: Thieme, 1988.

17. Smith AT, Greenlee MW, Singh KD, et al. The processing of firstand second-order motion in human visual cortex assessed by functional nagnetic resonance imaging (fMRI). J Netrosci 1998;18: 3816-30.

18. Cox R. AFNI: software for analysis and visualization of functional magnetic neuroimages. Comput Biomed Res 1996;29:162-73.

19. Freitag P, Greenlee MW, Lacina T, et al. Effect of eye movements 
on the magnitude of AMRL responses in extrastriate cortex during visual motion perception. Exp Brain Res 1998;119:409-14.

20. Spitzer WO, Skovron ML, Salmi LR, et al. Scientific monograph of the Quebec Task Force on Whiplash-Associated Disorders: redefining "whiplash" and its management. Spine 1995;20: 1S-73S.

21. Bogduk N, Teasell R. Whiplash. Arch Neurol 2000;57:590-1.

22. Cassidy JD, Carroll LJ, Côté P, et al. Effect of eliminating compensation for pain and suffering on the outcome of insurance claims for whiplash injury. $N$ Engl J Med 2000;342:1 179-86.

23. Ohelieniene D, Schrader H, Bovim G, et al. Pain after whiplash: a prospecitve controlled inception cohor study. JNNP 1999;66: 279-83.

24. Pearce JMS. A cricical appraisal of the chronic whiplash syndrome. JNNP 1999;66:273-6.

25. Bicik 1, Radanov BP, Schaefer $N$, er al. PET with 18fluorodeoxyglucose and HMPAO SPECT in late whiplash syndrome. Neurology 1998;51:345-50.

26. Ichise $M$, Chung D-G, Wang $P$, ec al. Te-99m-HMPAO SPECT, CT and MRI in the evaluation of patients with chronic traumatic brain injury: a correlation with neuropsychological performance. J Nud Med 1994;35:217-26.

27. O'Craven KM, Rosen BR, Kwong KK, et al. Voluntary attention modulates AMRI activity in human MT/MST. Newron 1997;18: 591-8.
28. Beauchamp MS, Cox RW, De Yoe EA. Graded effects of spatial and featural attention on human area $M T$ and associated motion processing areas.] Neurophysiol 1997;78:516-20.

29. Kasrner $S$, Pinsk MA, De W/cerd $P$, er al. Increased acrivity in human visual cortex during directed attention in the absence of visual stimulation. Newron 1999;22:751-61.

30. Plant GT, Laxer KD, Barbaro NM, et al. Impaired visual motion perception in the contralateral hemifield following unilateral posrerior cerebral lesions in humans. Brain 1993;116:1303-35.

31. Barton JJS, Sharpe JA, Raymond JE. Retinotopic and directional defects in motion discrimination in humans with cerebral lesions. Ann Neurol 1995;37:665-75.

32. Greenlce $\mathrm{MWW}$, Lang $\mathrm{H}-\mathrm{J}$, Mergner $T$, et al. Visual short term memory of stimulus velocity in patients with unilateral posterior brain damage. I Nethosci 1995; 15:2287-300.

33. Greenlee MW, Sinith AT. Detection and discrimination of firstand second-order motion in patients with unilateral brain damage. J Neurosci 1997;17:804-18.

34. Kimmig $\mathrm{H}$, Pinow C, Mergner T, er al. Smooth pursuic eye movements in patients with impaired visual mution perception. In: Mergner $T$, Hlavacka $F$, eds. Multisensary control of posture. New York: Plenum Press, 1995:325-9.

35. Barton JJS, Sharpe JA. Raymond JE. Directional defects in pursuit and motion perception in humans with unilateral cerebral lesions. Brain 1996;119:1535-9. 